\title{
EVALUATION OF THE NATIONAL COHESION STRATEGY. WHAT CAN WE LEARN FROM EVALUATION RECOMMENDATIONS?
}

\author{
KRZYSZTOF KASIANIUK, ${ }^{1}$ ROBERT SOBIECH ${ }^{2}$
}

Institute of Public Policy, Collegium Civitas, Warsaw, POLAND

${ }^{1}$ e-mail: krzysztof.kasianiuk@civitas.edu.pl

${ }^{2}$ e-mail: robert.sobiech@civitas.edu.pl

RECEIVED
ACCEPTED
JEL
CLASSIFICATION

KEYWORDS

ABSTRACT
18 January 2018

2 September 2018

$\mathrm{H} 10, \mathrm{H} 43, \mathrm{H} 50, \mathrm{H} 70$

evaluation, public policy, learning, National Cohesion Strategy, recommendations

Evaluation systems are important parts of public policy information feedback loop mechanisms. Evaluation studies gather a bulk of knowledge that may be used in improving public interventions. Recommendations formulated on the basis of evaluation studies play an important, but often neglected role in policy advice. As such, the quality of recommendations and mechanisms of their implementation become essential challenges for the evaluation system designers, evaluators, administrators and policy makers. The goal of the paper is to discover the key deficiencies of programs conducted within the National Cohesion Strategy (NCS) in Poland. The paper presents results of the study of 664 recommendations included in 56 evaluation studies. The study revealed a considerable inconsistency between the identified problems (mostly referred to deficiencies in program design) and proposed interventions that emphasized the changes in program management. The study also indicated that some evaluators had a little interest in future fate of the interventions, developing their recommendations not attaching enough importance to specifity of recommendations and their future implementation.

\section{Introduction}

Evaluation of public interventions is a growing challenge for modern states. Public interventions are multidimensional, and must be undertaken in a complex social, organizational and institutional setting. Many scholars note that evaluation fosters the improvement of governmental public interventions. It is through the existence of evaluation mechanisms that one can speak about the rationalization of public decisions (Alkin, 2004; 
Kaufmann, Kraay, Mastruzzi, 2009; OECD, 2013). Evaluation is also a prerequisite for systemic learning, as it is a basic mechanism for understanding logic and consequences of public interventions. Here, systemic learning in public domain means the process through which public institutions utilize the existing knowledge to improve functioning of institutions themselves and ameliorate social and economic problems.

One of the key prerequisites of systemic learning is a properly designed and guided evaluation system. The main difficulty, however, is the use of evaluation results in a multilevel and dispersed public evaluation system. A multilevel and dispersed public evaluation system is the one in which there are many actors responsible for evaluating public interventions situated at different levels of state organization. In many cases, these units are embedded in a multilevel network of evaluation organizations and institutions. One of the key question in such a system is how to facilitate a flow of expertise gathered in a bulk of evaluation studies and what should be the relations between managing authority and evaluators. Despite an undoubted advantages of designing, implementing and evaluating public interventions (mostly at the regional or local level) there is also a risk of fragmentation of existing expertise, and of limitation of the scope of evaluation use.

On the other hand, if knowledge contained in evaluation studies is to be useful, it should not only be appropriately processed during the decision-making process. It also should have appropriate characteristics that facilitate its use, even if there are important premises, such as political or substantive, that limit the evaluation use (Fleischer, Christie, 2009; Preskill, Caracelli, 1997).

According to Owen, who synthesized numerous studies on drivers of evaluation use, there are two crucial sets of factors facilitating evaluation use: 1) characteristics of the settings (where evaluation is planned and conducted), and 2) characteristics of the evaluation itself (Owen, 2007). It should be noted that there is no consensus whether there should be universal standards of evaluation or whether the evaluation studies should be adapted e.g. to the type of evaluation users or the country in which the evaluation is carried out (Bacmann et al., 2000; Segone, 2009). There seems to be a widespread agreement among scholars and practitioners though that a sound evaluation study should contain recommendations that are justified by evaluation study conclusions and lead to proposed course of actions.

At the same time, a brief review of manuals and guidance developed by international and national organizations illustrates the core characteristics that can be used as criteria of a solid recommendation.

"Recommendations are individual statements derived from the evidence that prescribe who should do what in the future. They provide suggestions for introducing improvements and/or identify matters for follow-up. Evaluators should explain the basis for making the recommendations, with linkages to the information collected in the evaluation. Both the interpretation of evidence and the basis for judgment should be addressed" (Canadian International Development Agency, 2002, p. 8).

The United Nations Evaluation Group, on the basis of a review of international practices, advises that the structure of recommendations should be: 1) limited in number (no more than 10); 2) prioritized and sequenced; 3) internally consistent and take into account interdependencies; 4) be aligned within groups (Improved Quality of Evaluation Recommendations Checklist, 2018, pp. 4-5).

Therefore, our study focused on two questions: 1) what problems were identified in the evaluation recommendations and what ameliorative actions or instruments were proposed in the recommendations, 2) to what extent the recommendations included in evaluation reports under scrutiny meet the above-mentioned standards of a solid recommendation. 
The latter question focused on three important recommendation features: a) the general specifity and clearness of recommendations, b) the specifity regarding recommendation users, and c) the timeframe for recommendations implementation.

\section{Aim and method of the studly}

The main aim of the study was to explore characteristics of the recommendations included in the evaluation studies commissioned within National Cohesion Strategy in the period of 2011-2015. This was primarily due to the fact that these evaluation studies constitute the bulk of evaluations of public programs in Poland (National Evaluation Unit, 2008; Rokicki, 2011). The analysis was based on the database of evaluation reports developed by the National Evaluation Unit in Polish Ministry of Development (National Evaluation Unit, 2015).

There were four overarching premises of the study. The first was that analysis of numerous recommendations may provide knowledge on the existing problems that appear in policy design and implementation, as well as knowledge on the proposed actions or instruments that should be applied to improve interventions undertaken within the cohesion strategy. The second was that the more clear and specific the recommendations, the better information it provides to the user. The third was that the recommendations should indicate the time of their implementation, providing information on existing bottlenecks in policy process. The fourth was that the recommendations should indicate specific users that are responsible for its implementation, allowing to identify key actors and stakeholders. Hence, we asked the five following research questions:

1. Problems. What problems and deficiencies were identified in the evaluation recommendations?

2. Solutions. What solutions (actions and instruments) were proposed to solve or ameliorate the identified problems?

3. Specifity: How specific and clear were the recommendations?

4. Timeframe for implementation: When, according to evaluators, the recommendation should be implemented?

5. Users of recommendation: Who should take action in order to implement recommendations?

Our analysis covered 221 evaluation reports (out of 1129 reports included in the NEU database) that were selected according to the following criteria:

1. Contracting authority (the authority that contracted the evaluation). Only the reports commissioned by central state and local-government administration were included.

2. Evaluation study size. The NEU database distinguishes 3 type of evaluation studies: "small", "medium", and "big". Only "big" and "medium" evaluation studies were selected.

3. Strategic thematic area. Evaluation studies conducted in the following areas: human resources development, regional and territorial development and good governance were selected.

4. Evaluation type. Ex-ante, on-going, and ex-post evaluations were selected.

Of 221 reports that met the above criteria, we randomly selected 56 reports that were examined in the study. All the studied reports included 664 recommendations. All the recommendations were subject of the content analysis. The coding scheme was based on conventional analysis, where coding categories were derived from the text data, as well on a directed approach, where coding categories referred to public policy theoretical models.

The vast majority of evaluations studies were commissioned by local-government administration $(80 \%$ of all the analyzed reports). Only $20 \%$ of the reports was ordered by the state administration. 


\section{Presentation of pesults}

\section{Identified problems and recommended actions}

The study showed that the key problem to which recommendations referred were deficiencies and mistakes in program design (Table 1). Such problems were indicated in $38 \%$ of all recommendations. Within this category, approximately, half of problems regarded program design and put emphasis on inadequate or ineffective instruments (excluding financial instruments). $14 \%$ of recommendations paid attention to problems with program management, focusing on inefficient use of resources (organizational, human and financial), and problems with monitoring and evaluating of programs. Problems with selection and recruitment (11\%) pointed at the bottlenecks in recruitment of beneficiaries, deficiencies in competition rules, and assessment of applications. The least frequent category stressed problems with external communication (9\%) with programs target groups and the society. The remaining problems were indicated less frequently ( $11 \%$ of all recommendations). Almost $13 \%$ of all recommendations did not refer to any problem, and $4 \%$ affirmed the need for continuation of intervention in an unchanged form.

Table 1. Problems identified in the recommendations

\begin{tabular}{lrc}
\hline \multicolumn{1}{c}{ Problems } & Number of recommendations & Percentage \\
\hline Construction of the program and mistakes in the program design & 250 & 38 \\
Deficiencies in program management & 93 & 14 \\
Lack of problems to which the recommendation is linked & 87 & 74 \\
Selection and recruitment to the program & 76 & 11 \\
Other problems & 57 & 11 \\
Communication with target groups, beneficiaries, society at large & 27 & 9 \\
Lack of problems - Affirmation of the existing interventions, or the need for continuation & 664 & 4 \\
\hline Total & & 100 \\
\hline
\end{tabular}

Source: own study.

The need for a redesign of numerous program interventions was hardly reflected in recommendations concerning necessary changes. Only $18 \%$ of recommendations proposed different modifications in program design. The bulk of recommendations (38\%) emphasized the need for changes in program management, improvements in external communication and modification of financial regulations. It worth noting that substantial part of recommendations $(26 \%)$, due to their generality, did not propose any specific actions of instruments. The discrepancy between the identified problems and proposed interventions turned out to be the major inconsistency of evaluation recommendations.

\section{Specifity of recommendations}

The analysis showed that many recommendations lacked enough specifity which would help in reconstructing the intentions of evaluators (Table 2). $9 \%$ of all recommendations were not specific at all, and $31 \%$ were classified as rather not specific. The recommendations that were included in the reports contracted out by the state administration were slightly more specific (64\%) than recommendations of reports contracted by local, or regional administration (58\%). 
Table 2. Specifity of recommendations according to contracting authority

\begin{tabular}{llcrrrrr} 
& \multicolumn{2}{c}{ State administration } & \multicolumn{2}{c}{$\begin{array}{c}\text { Local-government } \\
\text { administration }\end{array}$} & \multicolumn{2}{c}{ Total } \\
\hline Specifity & \multicolumn{2}{c}{ no. } & $\%$ & no. & $\%$ & no. & $\%$ \\
Specific recommendation & 24 & 25 & 137 & 24 & 161 & 24 \\
Rather specific recommendation & 37 & 39 & 195 & 34 & 232 & 35 \\
Rather not specific recommendation & 22 & 23 & 187 & 33 & 209 & 31 \\
Not specific recommendation & 12 & 13 & 50 & 9 & 62 & 9 \\
\hline Total & 95 & 100 & 569 & 100 & 664 & 100 \\
\hline
\end{tabular}

Source: own study.

The fact that nearly half of the recommendations contained only general tips recommendations which are difficult to translate into specific actions, suggest that for a large part of evaluators development of recommendations is an activity of secondary importance.

\section{Timeframe for implementing recommendations}

The study showed that nearly half of the recommendations (48\%) indicated a specific time for their implementation (usually a specific year or period in a given year - quarter, half year). Almost one third of the recommendations (29\%) proposed a very general timeframe (e.g. future programming period, next EU perspective, etc.). Such recommendation appeared more frequent in evaluations contracted by the local-government administration (30\%) than by evaluation contracted by the state administrations $(21 \%)$. The study also revealed that $20 \%$ of all recommendations did not specify any period of the implementation. This seems to confirm the thesis that a substantial part of evaluators does not attach great importance to implementation of the proposed changes, leaving decisions on this matter to the contracting institutions.

\section{Users of recommendations}

Majority of the recommendations (85\%) identified the users of recommendations. Only in case of $15 \%$ of recommendations there were no identified actors who should be responsible for their implementation.

The study revealed that the bulk of recommendations was addressed to institutions responsible for management of the evaluated interventions. It was both the case for state and local-government administration. More than $70 \%$ of all recommendations included in the reports commissioned by state administration were addressed to institutions of the state administration (39\% of recommendations addressed to managing institutions and nearly $33 \%$ at other users at state level). In case of reports that were commissioned by the local-government administration, $78 \%$ of recommendations were addressed to users at the same level.

It is worth noting that the vast majority of recommendations indicated only one user. Only $16 \%$ of recommendations indicated more than one institution that should be responsible for implementation. Given the many stakeholders involved in implementing the cohesion strategy, it is difficult to explain why most of the recommendations neglected the role of other actors. 


\section{Conclusions}

Analysis of the identified problems showed that development of policy instruments was a key deficiency in the implementation of the National Cohesion Strategy. It is worth noting however, that the need for a redesign of program interventions was hardly reflected in recommendations concerning necessary changes. The finding that $38 \%$ recommendations referred to deficiencies and mistakes in program design and only $18 \%$ of recommendations proposed different modifications in program design, showed a significant discrepancy between the diagnosed problems and the proposed interventions.

The study indicates that some evaluators had little interest in the future fate of the interventions. Development of recommendations seemed to be considered as a kind of routine activity. $13 \%$ of recommendations did not indicate any specific problem, and $20 \%$ of all recommendations did not propose any specific actions.

The study revealed that, firstly, the recommendations lacked specifity and clearness to a significant extent. Secondly, more than $70 \%$ of recommendations, regardless of the authority level commissioning the evaluation studies, aimed at users situated at the same level. Thirdly, nearly half of the recommendations were pointing to the specific moment in the calendar. These features seem to undermine the potential for coordination of evaluation studies in Poland, understood as a multilevel dispersed evaluation system. It is thus the reason to reflect on the future activities which would help such a system work in a more coordinated way.

The in-depth interpretation of the above findings requires not only the further studies on the recommendation content, but also a better understanding of relationships between the evaluators and the users of evaluation. In that sense, evaluation recommendations should be analysed not only according to the formal criteria of solid recommendation (like specifity or time frame) or in terms of accumulated knowledge on intervention programs, but also as an output of existing relations between evaluators and evaluation users. In that sense, studies on evaluation recommendations may link characteristics of evaluations with their institutional settings.

\section{Acknowledgments}

This research was possible due to support of Collegium Civitas internal grant program. We also want to thank Marcin Waszak and Marek Dudkiewicz whose competence in public sector programs and coding experience made this research richer.

\section{References}

Alkin, M.C. (2004). Evaluation roots: Tracing theorists' views and influences. Thousand Oaks: Sage.

Bacmann, N., Beywl, W., Chircop, S., Jang, S., Landert, C., Mukherjee, P., Widmer, T. (2000). The Program Evaluation Standards in International Settings. The Evaluation Center Occasional Papers Series. Retrieved from: https://www.ioce.net/download/reports/ ProgEvalStandards-Intl.pdf.

Canadian International Development Agency (2002). How to perform evaluations. Retrieved from: http://www.oecd.org/derec/ canada/35138852.pdf.

Fleischer, D.N., Christie, C.A. (2009). Evaluation use: Results from a survey of US American Evaluation Association members. American Journal of Evaluation, 30 (2), 158-175.

Improved Quality of Evaluation Recommendations Checklist (2018). Retrieved from: www.uneval.org/document/download/2876.

Kaufmann, D., Kraay, A., Mastruzzi, M. (2009). Governance matters VIII: aggregate and individual governance indicators, 1996-2008. Policy Research Working Paper, 4978. Washington, DC: World Bank.

National Evaluation Unit (2008). Evaluation process of the cohesion policy in Poland Summary of previous experience. Plans and challenges for the future. Retrieved from: www.archiwum.ewaluacja.gov.pl/Dokumenty_ewaluacyjne/Documents/eksp_02.pdf. 
National Evaluation Unit (2015). Evaluation Studies Dataset. Retrieved from: www.archiwum.ewaluacja.gov.pl/Wyniki/Documents/ 07102015_baza.xls.

OECD (2013). Poland: Implementing Strategic-State Capability. Retrieved from: https://doi.org/http://dx.doi.org/10.1787/978926 4201811-en.

Owen, J.M. (2007). Program evaluation: forms and approaches. London: Guilford Press.

Preskill, H., Caracelli, V. (1997). Current and developing conceptions of use: Evaluation use TIG survey results. Evaluation Practice, 18 (3), 209-225.

Rokicki, B. (2011). System monitorowania i ewaluacji polityki spójności w Polsce. Gospodarka Narodowa, 3, 87-103.

Segone, M. (ed.) (2009). Country-led monitoring and evaluation systems. Better evidence, better policies, better development results. Country-led monitoring and evaluation systems. UNICEF.

Cite this apticle as: Kasianiuk, K., Sobiech, R. (2018). Evaluation of the National Cohesion Strategy. What can we learn from evaluation recommendations? European Journal of Service Management, 3 (27/2), 189-195. DOI: 10.18276/ejsm.2018.27/2-23. 